Ana María Martínez de la Escalera

\title{
Coleridge, el poeta y un improbable Kant
}

Prólogo

¿Qué une Los sueños de un visionario con The Rime of the Ancient Mariner? ¿La Crítica de la Razón Pura con On the principles of Political Knowledge? ¿Quizá una época, acaso un mismo amor al saber? Y, ¿qué decir de la relación entre un poeta y un filósofo? Tal vez, pese a la idea que comúnmente nos hacemos de ellos y de sus respectivas disciplinas; apasionado uno y una, sobrio el otro y la otra, ¿habría algo más allá de géneros y estilos que podría unirlos? Si lo anterior puede ser preguntado en general de muchos filósofos y de otros tantos poetas, ¿qué diremos específicamente de Coleridge y Kant? Por cierto, jamás llegaron a conocerse directamente sino es mediante sus obras: Coleridge leyó con seguridad a Kant, dicen sus críticos (Stauffer, IX-XXIV); del alemán poco se sabe de sus gustos literarios. Como buen alemán, con toda seguridad despreciaba el ensayo por considerar, como escribiera Adorno en el siglo xx, que "reproduce lo amado y lo odiado, en vez de representar el espíritu -conforme al modelo de una ilimitada mística de trabajo —como 
creación a partir de la nada" (Adorno, 10). ${ }^{1}$ Adorno llevaba la razón cuando describía a sus connacionales como individuos que desprecian la "libertad de espíritu" (Adorno, 10) y prefieren vivir subordinados. Kant había hecho notar que la madurez del ciudadano implica criticar, buscar la verdad pero obedecer. Tener el valor de servirse de la razón no debía impedir subordinar esa razón al arbitrio superior del monarca. Para el alemán el ciudadano es ante todo un hombre, es decir un animal que "busca su señor" (Kant, 50-51), según observa en el Sexto Principio de su Idea de una historia universal en sentido cosmopolita del año 1786.

Se dice que Coleridge tenía en mente las ideas kantianas al escribir varios de sus ensayos más célebres. Basta fijarse en sus títulos para comprenderlo: On the Grounds of Morals and Religion, and the Discipline of the Mind Requisite for a True Inderstanding of the Same, On the Principles of Political Knowledge ya antes citado, sus ensayos sobre Bacon al que, igual que Kant, admiraba. Kant dedicó a Bacon la primera de sus Críticas, Coleridge a su vez, lo cita en sus ensayos sobre el método, sobre el propósito del hombre y la Naturaleza, sobre el significado de la existencia. Y el ensayo es el modo más expedito de la admiración sin escrúpulos a la que se refiere Adorno. La relación amor-odio con lo que se admira, la emulación tal y como los griegos y después los romanos practica-

1 "En Alemania, el ensayo provoca rechazo porque reclama libertad del espíritu, esa libertad que, desde el fracaso en tiempos de Leibniz de una apenas tibia Ilustración [...], no se ha desplegado adecuadamente hasta nuestros días, sino que siempre estuvo dispuesta a proclamar su subordinación a cualesquiera instancias como si ése fuera su propio destino. Sólo que el ensayo no permite que le prescriban su campo de acción. En vez de producir algo científicamente o de crearlo artísticamente, su esfuerzo refleja todavía el ocio de lo infantil, que se enciende sin escrúpulos frente a lo que otros ya hicieron. El ensayo reproduce lo amado y lo odiado, en vez de representar el espíritu - conforme al modelo de una ilimitada mística de trabajo- como creación a partir de la nada. La suerte y el juego le son esenciales". T.W. Adorno, "El ensayo como forma" en Notas de literatura, Ariel, España, 1961, p. 12. 
ron, es la manifestación más sublime, más estética quizá, de la memoria y la tradición. Kant también lo sabía. En un opúsculo muy citado escrito en 1798 escribió respecto de la Revolución francesa: "¡Y con qué exaltación simpatizó entonces el público espectador desde fuera, sin la menor intención de tomar parte!" (Kant,107). Así fue como Coleridge simpatizó con Kant, el cual habría de estimular su propia escritura sin intentar ejercer de filósofo: le bastó ese universo llamado literatura. En efecto, sus ensayos son eminentemente literarios. Aúnan a la relación pasional con las citas la simpatía libre, desprejuiciada y desinteresada que Kant indicó era la marca de la reflexión estética y de lo sublime, sin el menor deseo de sustituir u ocupar el lugar del otro: en ese sentido el escritor inglés fue un esteta. Prefirió el juego, característica notable del arte autónomo como indicó Huizinga en su Homo ludens, a la observancia de tabúes religiosos y políticos. Defendió la autonomía de la poesía como esfera del libre intercambio de opiniones y no como el refugio del libre albedrío, íntimo y egoísta. Muchos años antes que Coleridge, Hume que ejerció gran influencia también sobre el pensamiento kantiano había predicho que el ensayo era la forma que la conversación debía tomar en el futuro si de lo que se trataba era de defender y sostener esa esfera pública base de cualquier república. Pensaba Hume que el ensayo era la manera adecuada de tratar la cosa (res) pública, de establecer una conversación entre el pensamiento riguroso y el apasionamiento de los intereses cotidianos, los deseos y los caprichos singulares. Creía que no existía mejor forma de vincular lo universal a lo particular, es decir de dar sentido a la existencia, que la conversación entre los hombres y las mujeres. Estaba convencido también que en el ensayo se realizaba la finalidad de la conversación que es la de edificar lo común, lo público, aquello en lo que nos reconocemos como ciudadanos. Hume definió lo que Coleridge practicó: la conversación con los otros, con el pasado del pensamiento y con el presente de 
la verdad. En fin fue, además de humiano en sus deseos, un kantiano practicante. Lo público, escribió Kant después de Hume, es la esfera donde lo civil y lo político tienen lugar como intercambio de opiniones, deliberación y toma de decisiones comunes en la ausencia de un criterio único y absoluto que dirija el intercambio. Los asuntos de los hombres en sociedad nunca han sido sencillos, pero al menos - y Kant le agradecía a la naturaleza-, la fuerza del vivir en común se sale con la suya. ¡Y qué fuerza! Kant y Coleridge sabían que ella residía en la razón disciplinada pero pasional, apasionada por preguntar aquello que ni ella misma puede contestar.

\section{Kant, el filósofo}

Había de nacer Kant un 22 de abril de 1724 en Könisberg. Como a él le hubiera gustado, de la vida profesional del filósofo se sabe estrictamente lo necesario: estudió los clásicos griegos y latinos en la Real Academia de Federico y en 1740 entró a la Universidad. De ahí hasta 1760 se habría dedicado a dar conferencias privadas, a desempeñarse como preceptor sin relación alguna con la institución académica de la época, si exceptuamos alguna que otra carte de recomendación que expidiera alguno de sus maestros. Esto es, hasta que en 1770 se lo nombró para la cátedra de matemáticas, que el decidió cambiar en seguida por la de lógica y metafísica, más afín a sus intereses. En 1781 dio a la prensa la Crítica de la Razón Pura; tras escribir y publicar sus dos críticas restantes, murió en 1804.

De Quincy, biógrafo enamorado de los últimos y tristes años del pensador alemán, comentaría con acierto que si bien las obras de Kant eran casi desconocidas para el público inglés del siglo XIX, no sucedía lo mismo con su nombre, al que poco a poco se asoció una leyenda académica que hasta hoy persiste, la del estudioso puntual hasta la exageración, el soltero em- 
pedernido que prefirió la academia a las delicias dudosas del matrimonio y la descendencia. Más allá de sus supuestas extravagancias Kant fue quien en realidad denunció las extravagancias del gusto de su época por la charlatanería. Swedenborg, desafortunadamente célebre, había logrado hacerla pasar por metafísica. Kant intentó defender la razón frente a sus enemigos más acérrimos, no la mentira o el prejuicio sino la ingenuidad y la credulidad de una ciudadanía vuelta cada vez más un espectador pasivo de su propia historia. Intentó mediante sus escritos de juventud instar a los lectores a esa maduración del ánimo y del juicio que definió, en su madurez, con la fórmula Sapere aude ( $i$ Ten el valor de pensar por tí mismo!).

Esta defensa lo llevaría a escribir unos pocos años antes de su famosa primera Crítica una obrita curiosa. La singularidad de la misma no depende ni de su pretensión ni de sus conclusiones, ambas compartidas por los intelectuales ilustrados de Francia y Alemania. Como es sabido los ilustrados habían hecho suya la empresa de denunciar como habladurías la superchería y los malos oficios de los charlatanes, sustituyendo la vieja costumbre del patíbulo inquisitorial por la inocua ironía y el relativamente benigno desenmascaramiento. En efecto, años antes de escribir la primera de sus críticas, la Crítica de la Razón Pura, Kant habría dado a la prensa en 1766 una pequeña obrita Los sueños de un visionario donde tras repasar los empleos que en su lengua tiene la palabra espíritu, declaraba su imposibilidad o contrafacticidad, según gustamos decir en nuestros días, y desenmascaraba el engaño de quienes tras las palabras de "espíritu" y "ángel" ocultan intereses nefandos y la enfermedad del alma. Exposición crítica de las fantasmagorías de un visionario que sirve no sólo de denuncia del saber metafísico mal fundamentado sino como ejemplo de buen proceder reflexivo. Obra escrita en nombre del progreso de la filosofía y contra la frivolidad de Swedenborg a quien en el capítulo cuarto expone sin miramientos, y así de todo filósofo vuelto mer- 
cader de sombras. De más estấdecir que se trata de una batalla librada y ganada por los ilustrados contra la superchería y el oscurantismo religiosos de salón. En el capítulo tercero Kant parece reducir la fantasía a una enfermedad que afecta los sentidos pero que no toca el entendimiento, de ahí que resultaría vano esperar una cura procedente de la razón: el fantasioso, el enfermo en definitiva no pueden superar sus vanas sensaciones. Distinción harto conocida y un tanto radicalizada entre la sensación y el entendimiento. Kant argumenta que es tarea de la filosofía ser la "balanza del entendimiento" que limpia de prejuicios el alma y extirpa las ciegas sumisiones a saberes imaginarios. El enfermo que tal vez no sea capaz de curarse a sí mismo tras la lectura, dará ocasión al lector avisado de efectuar una cura sobre terceros menos afortunados.

Kant representó extremadamente bien los intereses de una Ilustración, o al menos de una de sus tendencias, al defender la razón sobre los excesos más desafortunados de la fantasía. Son los excesos los que Kant opina nefastos y no la fantasía en sí misma, cuyo uso adecuado dentro de la arquitectónica de la razón, es tan necesario como el uso del juicio y la crítica. El futuro cosmopolita del mundo humano, el mismo progreso hacia lo mejor, la historia universal como posibilidad no son sino muestras de ideas que sólo la fantasía le dicta en el oído a la razón. La historia y la política están, todas ellas, llenas de fantasía y sobre todo de imaginación. La poesía, la literatura y el arte, están repletos de imaginación. La relación entre un filósofo y un poeta no parece tan extraña entonces. Hay un momento y un lugar donde la razón y su afán de seguir extendiéndose sobre el universo se alía con la imaginación sin la cual no podría interrogarse sobre lo que ella misma desconoce. En breve, no hay siquiera porvenir de lo humano sin la fantasía dirigida por la imaginación.

Sabemos que la tradición filosófica había definido la imaginación como una facultad o actividad mental distinta de la re- 
presentación y de la memoria. Su especificidad consistía en combinar elementos provenientes de la representación sensible, ordenarlos y conservar las nuevas unidades así logradas. Sin embargo Kant reparó en que la imaginación no podía sino ser una forma de representación antes que pura vivencia fantasiosa o fantasmática. Sin imaginación las presentaciones al sentido no podrían ser ordenadas. Antes, Hume había reducido la imaginación a la representación: menos vívida que la representación de objetos, pertenecería de igual modo a ésta de la cual se diferenciaría por el grado de viveza. Kant conocía bien a Hume. El alemán fue en la realización de sus afanes ilustrados un lector cuidadoso y un agudo crítico del empirismo inglés, que en ese entonces (finales del siglo xviII y principios del XIX), aparecía como el campeón del sentido común frente al docto lenguaje alemán de la filosofía, movido más por la necesidad de absolutos que por un interés pragmático en la vida. Kant no será el único alemán atraído por el conciso y sano espíritu inglés; Leibniz había celebrado - antes de criticarlael alma inglesa y Nietzsche, después de ambos, habría de encontrar en la lectura de Hume un escritor afín y un solaz frente a la incomprensión de sus conacionales. Aconsejado por sus lecturas humeanas, Kant reduce, a su vez, la imaginación al objeto. Reconoce sin embargo que ella hace posible la unidad de la diversidad de lo dado en la intuición. Cuando consideramos al entendimiento lo pensamos como la unidad de la apercepción en relación con la síntesis de la imaginación. Sin esta última el conocimiento sería imposible. Sin imaginación las apariencias jamás se nos harían patentes en modelos reconocibles y por lo tanto comunicables. La imaginación es, además de productiva, consciente de esa facultad de síntesis ordenada de las intuiciones. En cualquier caso la imaginación precede a la experiencia, produciendo las intuiciones de espacio y tiempo donde colocamos los datos de la sensibilidad. La imaginación es así puramente formativa. Pero también lo que 
llamamos imaginación es una facultad reproductora o poética, que lleva al entendimiento una intuición tenida precedentemente. No puede crear nada nuevo que no estuviese antes en la sensibilidad. Es decir, que él previamente no hubiese representado. Se revela en ese instante un prejuicio del que participan el empirismo de Locke y el trascendentalismo kantiano: ambos están convencidos, o más bien persuadidos, que sólo es posible conocer (y disfrutar) lo cognoscible y disfrutable. Esto es aquello que previamente hubiéramos, mediante nuestra actividad o nuestro trabajo, dispuesto como tal. ¿Qué "espíritu de una ilimitada mística del trabajo" susurró al oído kantiano un prejuicio tan lamentable? ¿Acaso el poeta podía estar de acuerdo con ese empobrecimiento de la experiencia poética que el filósofo alemán preconizaba? Es en la definición de la imaginación y en el papel privilegiado que ambos conceden a la misma donde Kant y Coleridge se separan. La imaginación en Kant no es sino trabajo solidificado, pasado en suma, mientras que en el poeta es barrunto de un futuro mejor. Pero esta diferencia no los hace diversos, incluso parece acercarlos: la imaginación es en ambos una fuerza histórica que juega con el pasado, el presente y el futuro en forma caprichosa, artística si se quiere.

¿Dónde reside la fuerza de ese poder de la imaginación, o el "poder hacer" (performatividad) de esa fuerza formativa, ya sea del pasado o del futuro, sino en el acto poético, literario, en la obra de arte? Kant parece haberlo presentido en la Crítica del Juicio y Coleridge, sin duda, lo practicó; al igual que, en su momento, el inglés supo poner en práctica lo que su compatriota Hume había soñado filosóficamente un tiempo antes...

Es sabido que Coleridge se decanta por una imaginación no distinta de la fantasía, y como ella descrita como una fuerza. Sin embargo no es la conclusión poco original o tipicamente de su época lo que me interesa señalar aquí sino cómo la expo- 
ne. Coleridge comienza distinguiendo fantasía e imaginación, una procede del griego, la otra del latín. Discernir opuestos es lo que hace Kant en Los sueños de un visionario como antecedente de la crítica. A su vez, Coleridge propone distinguir la Fantasía (Fancy) que es griega, de la imaginación (Imagination) que es latina; fantasía e imaginación, palabras diferentes, culturas diferentes, modos de ser differentes que la lengua inglesa traslapa al volverlos sinónimos. En toda cultura se tratará, desde el punto de vista del pensador, de des-sinonimizarlas. Coleridge asumiendo la tarea del pensamiento se propone investigar el principio seminal de su diferencia, y de ahí deducir el grado de la fuerza (fantasiosa o imaginaria). Pero hay que considerar otras fuerzas. El intelecto kantiano es igualmente una fuerza plástica que trabaja sobre el material de nuestras sensaciones, sin forma. Fuerza plástica, sin contenido al igual que la de la imaginación. La imaginación para ambos, poeta y filósofo, no tiene que ver con contenidos, ni con lo irreal, verdadero o falso de lo que es imaginado, sino con su condición plástica. La plasticidad que está en la lengua de la imaginación parece imponerse con la misma fuerza para el poeta, bajo la forma de la linealidad de la articulación del verso, que para el filósofo, quien considera esa fuerza plástica como lo propio de la lengua del entendimiento. Hay además una imaginación primaria y una secundaria para el poeta. La primera es el agente de la percepcion humana. Fuerza de repetición en la mente finita del eterno acto de creacion del infinito "Yo soy" esgrimido por el poeta. La secundaria se distingue de la anterior por el tipo y el grado de ejercicio de esa fuerza y coexiste con la voluntad. Disuelve, difumina, disipa para re-crear; y, cuando esto es imposible, lucha por idealizar y unificar. Es vital pese a que sus objetos sean fijos o muertos. Eso que Coleridge llama fancy sólo trabaja sobre lo fijo y definitivo. Es sólo un modo de la memoria emancipado del orden del tiempo y el espacio, mientras se mezcla y se modifica por el fenómeno de la voluntad que lla- 
mamos "escoger" (choice), que no es sino un acto del juicio pero también la oportunidad y ocasión de hacer o decidir entre lo mejor o lo peor (choice). La imaginación, que en inglés se llama fancy, recibe su material de la ley de asociación que la precede, pero aún así debe escoger: lo que la imaginación proclama es la necesidad absoluta de escoger, de elegir.

Hablemos nuevamente del hombre que fue Coleridge. Nacido en 1772, el futuro escritor completaba su educación en Cambridge, entre el 91 y el 93, en un ambiente que combinaba el sólido sentido común y una ideología - ¿o debemos decir prejuicios? - salpicada de un esteticismo difuso muy de la época. De ambos, sentido común y prejuicio, habría de servirse una vez que se sintió preparado suficientemente para la tarea de escritor. Y entonces conoció y se asoció a Wordsworth. Con seguridad habría conocido a Hume durante sus años de universitario, visitando librerías y bibliotecas. A Kànt es más difícil saber cuando y cómo lo conoció. Sabemos que viajó a Alemania entre el 98 y el 99; también sabemos que estudió allí. ¿Había conocido las obras de Kant con anterioridad? Es poco probable pero todo parece dirigirlo al filósofo alemán: Coleridge parece impresionado por la necesidad de distinguir entendimiento de la necedad de sus contemporáneos. Es posible suponer que Coleridge también encontró en Kant el respeto al sentido común pragmático, casi humeano, sin la obvia rendición anglosajona ante sus demandas, la búsqueda de trascendencia en la idea de Humanidad como finalidad del Mundo y la Naturaleza, y finalmente, la defensa sutil y aguda del entendimiento y la razón como prueba de la necesidad de lo humano. Aun así resulta difícil imaginar una reconciliación entre el pensamiento inglés y el alemán presidida por la Poesía de Wordsworth. Pero sucedió, y a ese acontecimiento le llamamos la poética de Coleridge.

En el ensayo crítico sobre los usos de lo natural en la poesía y en la glosa que acompañó en 1817 la publicación del poema 
The Rime of the Ancient Mariner Coleridge enuncia y formula su planteamiento poético. El hecho de que el poema vaya acompañado de un texto explicativo es en sí mismo interesante. No se limita a otorgar claridad al poema narrativo, a explicar que éste fue hecho a imitación de las baladas tradicionales sobre lo sobrenatural, o a llamar la atención sobre ciertos símbolos, como por ejemplo el énfasis que la glosa pone sobre la aparición del barco fantasma portando los lemas de "Muerte" y "Vida-en-la-Muerte". Mediante ejemplos contundentes hace ver como la imaginación (simbolizada por la Luna) junto con la razón (simbolizada por el Sol) postulan la inteligencia humana como entidad absoluta, como presencia, no sólo como operación o funcionamiento. Ambos símbolos son viejos conocidos nuestros y de los poetas románticos, pero, y he aquí lo notable, proceden ambos del trabajo de la imaginación (simbolización de material precedente) que, como sabemos por Kant, conserva ordenados en la memoria y postula ciertos temas en la tradición occidental. La Luna, que oculta o vela los horrores del mundo y los hace soportables, es también la fuerza que trasmite el tesoro de la sabiduría sin ser ella misma ese tesoro. La imaginación es facultad sin contenido, fuerza que conforma antes que lo conformado.

Cobijado por la luz de la Luna el viejo marino, narrador por excelencia, bendice a las serpientes de mar, por cierto sus enemigas. "The shadow of the ship/ I watched the water snakes:/ They moved in tracks of shining white, And when they reared, the elfish light/ Fell off in hoary flakes." Y entonces las bendice en su corazón buscando su perdón, el perdón de todas las criaturas a las que había ofendido cruelmente al matar al Albatros. La narración que el marino cuenta al huésped, al igual que la bendición de las serpientes, logran finalmente, una vez oídas o leídas, o leídas y oídas, reunimos con la naturaleza agraviada. Ese reencuentro sólo puede ser, el día de hoy, imaginario, es decir postulado. El reencuentro pertenece, como Kant sabía, 
a esas ideas de la razón reflexivas que como la idea de Dios o la de Mundo, aún no han sido completamente definidas o hechas realidad más que como postulación vacía. De su inacabamiento o indefinición dependerá, en última instancia, la salvación humana, la capacidad de regresar a la Naturaleza.

A diferencia de sus contemporáneos británicos, Coleridge no creía desproporcionados los escritos especulativos de Kant. Ni siquiera sus prejuicios. El amor del inglés por la Naturaleza no le había hecho olvidar la consigna kantiana de que la finalidad de ella es servir al Hombre. Desproporcionado como hoy nos parece, Kant sostenía el argumento de la superioridad del hombre sobre lo creado. En 1786 escribía lo siguiente: "El cuarto y último paso de esa razón que eleva a los hombres muy por encima de la sociedad con los animales, consistió en que comprendió el hombre (no más que barruntándolo) que él constituía el genuino fin de la Naturaleza y nada de lo que rebulle sobre la tierra podía hacerle en esto la competencia" (Kant,75). Finalidad ontológica que en Coleridge se percibe como finalidad del sentido. En la Rima del viejo marino el albatros abatido cumple su cometido a cabalidad: le muestra al viejo y a nosotros, sus lectores, el sentido moral del mundo y de esa finalidad. Así lo creía Kant. En Historia profética de la Humanidad, apartado 7 del opúsculo Si el género humano se halla en progreso constante hacia mejor argumenta como sigue:

Aquello que nos muestra a la razón como pura y, al mismo tiempo, en virtud de su grande influencia, que hace época, como deber reconocido por el alma de los hombres, que afecta al género humano en la totalidad de su asociación (non singulorum, sed.universorum), y cuyo esperanzado logro y cuya procuración nos entusiasma con una participación tan general y $\tan$ desinteresada, tiene que ser algo fundamentalmente moral (Kant, 107-108). 
Lo que Coleridge espera que entusiasme a su lector, de forma general y desinteresada, es la moralidad de la culpa del viejo. Se trata de un progreso de la razón y por ende del género humano el que la culpa mítica o teológica sea sustituída por la culpa moral. Porque podemos comprender (el entusiasmo general y desinteresado kantiano), somos Hombres o estamos en vías de convertirnos en tales: hombres con mayúscula y no simplemente seres tomados en su singularidad y diferencia. En esta idea del progreso de la Humanidad y no de los hombres y las mujeres reside el profundo parecido entre Coleridge y Kant, ambos, sabiéndolo secretamente, anhelan la seguridad del platonismo frente a la temible diferencia. Si el ancient mariner se salva, o es finalmente salvado no será en carne propia o en su nombre, sino en nombre de una Humanidad que debe ("constrained to hear his tale" [parte 1], obligado, constreñido, subyugado como el invitado a la boda) volver la mirada hacia atrás (oir como el invitado a la boda "a pesar de sí mismo": "Yet he cannot choose but hear" [línea 38]), hacia su pasado penoso y primitivo ("There was a ship," quoth he" [línea 10]. En efecto, "había una vez un barco"), ${ }^{2}$ y saludarlo como un peldaño necesario en el camino ominoso de la especie. a la conquista de la Moral (sobre la biología). En esto hoy podemos ser profundamente antikantianos. Hoy creemos más en "los hombres y las mujeres" que en la Humanidad en general. Estamos dispuestos a pensar que ciertas costumbres son mejores que otras, o más preferibles una vez que las hemos confrontado con otras diferentes. Pero ya nos es muy difícil creer como Kant o Coleridge, que la idea de Historia universal, $\mathrm{Hu}$ -

2 Un anciano marinero se encuentra tres galantes invitados a una boda y detiene a uno de ellos. El invitado es de alguna forma encantado por la extraña figura de otro tiempo del viejo y así obligado a oír su historia que como el lector recordará, es la historia de un crimen. El viejo ha dado una muerte sin sentido a un bello albatros. Su culpa lo perseguirá, y al lector, a lo largo de un poema escrito en una lengua nostálgica, con sabor a cosa olvidada. 
manidad u Hombre regulen de alguna manera la deliberación y la toma de decisiones sobre lo que en un momento dado nos interesa en común. Lo que el vocablo "Hombre" quiere decir, así como el sentido que otorgamos a la expresión "humano", no queda fuera del debate en una exterioridad a prueba de pasiones o intereses, sino que, por el contrario, es lo que está en el centro de la discusión contemporánea sobre el futuro del mundo.

Bibliografia

Adorno, T. W., Notas de literatura, Ariel, España, 1961.

Coleridge, Samuel Taylor, Selected Poetry and Prose of... (Donald A. Stauffer ed.), Random House, Nueva York, 1951.

Kant, Emmanuel, Filosofía de la Historia, Fondo de Cultura Económica, México, 1985.

VITAL, Alberto (Selección, prólogo y notas), Ensayistas alemanes (Siglos XVIII-XIX), Conaculta, México, 1995. 